\title{
Modernización urbana y exclusión social en Cartagena de Indias, una mirada desde la prensa local
}

Urban Modernization and Social Exclusion in Cartagena de Indias, a View from the Local News

\author{
Modernização urbana e exclusão social em Cartagena \\ de Índias, um olhar desde a imprensa local
}

Fabricio Fabián Valdemar Villegas*

Recibido: 13 de septiembre de 2014

Aprobado: 23 de agosto de 2016

Doi: http://dx.doi.org/10.12804/revistas.urosario.edu.co/territorios/a.5157

Para citar este artículo:

Valdemar Villegas, F.F. (2017). Modernización urbana y exclusión social en Cartagena de Indias, una mirada desde la prensa local. Territorios (36), 159-188. Doi: http://dx.doi.org/10.12804/revistas.urosario.edu. co/territorios/a.5157

* Licenciado en Ciencias
de la Educación, con es-
pecialidad en Ciencias
Sociales (Universidad del
Atlántico, 1992); Especia-
lista en Pedagogia para el
desarrollo del aprendizaje
autónomo (UNAD, 2003);
Magísteren Historia (Uni-
versidad Pedagógicay Tec-
nológica de Colombia, se-
de Tunja, 2012); docente
de cátedra del programa
de Historia de la Facul-
tad de Ciencias Huma-
nas de la Universidad de
Cartagena y Maestro del
Distrito de Cartagena de
Indias. Correo electróni-
co: fayun68@gmail.com.
OR CID: http://orcid.
org/0000-0003-3175-3980 
Palabras clave

Cartagena de Indias, politica urbana, modernización, prensa local, exclusión social.

Keywords

Cartagena de Indias, urban policy, modernization, local news, social exclusion.

Palavras-chave

Cartagena de Índias, politica urbana, modernização, imprensa local, exclusão social.

\section{territarias 36} 160

\section{RESUMEN}

El Plan Pearson de 1914 y el Plano Regulador de 1948 constituyeron los horizontes de la planificación urbana de la ciudad de Cartagena de Indias durante la primera mitad del siglo XX. El propósito de ambos proyectos, pese a sus particulares disposiciones, estaba orientado hacia la modernización del entorno urbano. Empresa que, en el ideario de las élites locales y nacionales, estaba garantizada puesto que las dos propuestas de ciudad se acomodaban a los modelos urbanos euro-centristas y priorizaban el componente morfológico. Los ejes de ésta pretendida restauración fueron la higienización, la implementación de servicios públicos y el equipamiento urbano. La adecuación de la superestructura y de la infraestructura urbana sería la base del despegue económico que por décadas le fue esquivo a la ciudad. Sin embargo, el ideario de las autoridades formulado tanto en el Plan Pearson como en el Plano Regulador contrastaría con la mirada crítica de la prensa local que, en muchos momentos, fungía como oposición política y en otros casos retrataba a través de sus plumas las verosimilitudes de una ciudad en donde la exclusión fue el rasgo sobresaliente de su vida social.

\section{ABSTRACT}

Alpha. The Pearson plan of 1914 and the Master Plan of 1948 constituted the horizons of the urban plan of the city of Cartagena de Indias during the first half of the $20^{\text {th }}$ Century. The purpose of both plans, despite their particular dispositions, was oriented to the modernization of the urban environment. A venture that, in the idea of the local and national elites, was guaranteed since both city plans accommodated to the Eurocentric urban models and prioritized the morphologic component. The axes of this pretended restoration were the sanitization, the public service implementation and the urban equipment. The adaptation of the urban superstructure and the infrastructure would be the foundation for the economic lift off that for decades eluded the city. However, the authorities' idea - formulated in the Pearson plan and in the Master plan - would contrast with the critical view of the local news, which in many moments, served as political opposition, and in other cases portrayed, through its writing, the verisimilitudes of a city where the exclusion was the outstanding trait of its social life.

\section{RESUMO}

O Plano Pearson de 1914 e o Plano Regulador de 1948 constituíram os horizontes da planificação urbana da cidade de Cartagena de Índias durante a primeira metade do século XX. O propósito de ambos os projetos, em que pese às suas particulares disposições, estava orientado à modernização do entorno urbano. Empresa que, no ideário das elites locais e nacionais, estava garantida sendo que as duas propostas de cidade se acomodavam aos modelos urbanos euro centristas e priorizavam o componente morfológico. Os eixos desta pretendida restauração foram a higienização, a implementação de serviços públicos e o equipamento urbano. A adequação da superestrutura e da infraestrutura urbana seria a base da descolagem económica que por décadas lhe foi esquivo à cidade. $\mathrm{N}$ entanto, o ideário das autoridades formulado tanto no Plano Pearson quanto no Plano Regulador contrastaria com o olhar crítico da imprensa local que, em muitos momentos, exercia como oposição política e em outros casos retratava através da suas canetas as verossimilitudes de uma cidade onde a exclusão foi o rasgo sobressalente da sua vida social. 
El propósito de este artículo es analizar los rasgos de una pretendida pero precaria modernización en la ciudad de Cartagena de Indias durante la primera mitad del siglo XX. Restauración que fue un proyecto del gobierno nacional y, en menor escala, de las autoridades locales. Sus limitados alcances se explican porque, siguiendo los argumentos de Corredor (2001), el contexto en el que fue pensada respondía a unas lógicas económicas y políticas modernas y su aplicación se activó en un universo distinto. El resultado del contraste fue la marginación y exclusión social en ciertos sectores populares de Cartagena, ante la urgente necesidad de las elites de reconfigurar la ciudad de acuerdo a su proyecto de acumulación. La política urbana encaminada al desarrollo económico y social, bajo el encuadre de la modernización, favoreció, entonces, el carácter de Cartagena de ciudad dual (Fuente, 1999) ${ }^{1}$. El equipamiento urbano $^{2}$ que se adquirió estuvo al servicio de ésta segmentación espacial.

En la lógica del análisis que se pretende se entiende la exclusión social como concepto multifactorial. Puede explicarse por factores como el desempleo, la pobreza severa, la falta de asistencia en servicios educativo y de salud, precariedad laboral, aislamiento relacional y dificultades económicas en el hogar, por lo que las dimensiones de esta realidad son de naturaleza laboral, económica, cultural, personal y social. De lo anterior se deriva que la exclusión social sea un proceso muy heterogéneo que afecta a muchos y muy diversos grupos. Como fenómeno estructural es posible abordarlo de forma estratégica, a través de políticas efectivas que promuevan las prácticas de inclusión, ya que, en muchos casos, es producto de políticas ineficaces (Hernández, 2008).

En este artículo se presenta una relación de los elementos constitutivos de la deseada modernización presentes en el Plan Pearson de 1914 (figura 1) y en el Plano Regulador de 1948. Para efectos del análisis historiográfico que se pretende se ha recurrido a una multiplicidad de fuentes primarias principalmente relacionadas con la prensa local que dan cuenta, si se quiere, del debate suscitado entre las autoridades que impulsaron los planes y una opinión pública que, sostenidamente y durante más de treinta años, observaba cómo la construcción de la ciudad se sustentaba sobre un discurso imaginado. En este sentido compartimos la idea de la profesora Bonilla Vélez cuando afirma que la prensa, hija de la modernidad, es una fuente imprescindible en la recuperación de nuestra memoria colectiva y es una herramienta útil en la reconstrucción historiográfica. En ésta se encuentran representados los movimientos de la ciudad, la cotidianidad, los prejuicios, costumbres y discursos en tanto que ella, además de informar, también analiza el momento histórico de una sociedad (Bonilla, 2012, pp. 51-90). Esta convicción ha implicado la revisión de la prensa existente en el Archivo Histórico de Cartagena (AHC) y la Biblioteca Bartolomé Calvo (BBC). Periódicos como El Fígaro, El Porvenir, La Época, La Patria, La Unión Comercial, El Diario de la Costa
${ }^{1}$ Roberto Serge (1999) define a la ciudad dual a la que alberga en su recinto, aunque en áreas diferentes, a dos clases sociales bien diferenciadas por su nivel económico: ricos y pobres. La ciudad de los pobres es físicamente insalubre, socialmente inmoral, económicamente pobrísima, culturalmente inexistente y politicamente también inexistente... La ciudad de los ricos podría definirse por todo lo contrario: fisicamente bella, socialmente intachable (o al menos, se pretende), económicamente rica, culturalmente elevada y politicamente activa.

${ }^{2}$ Se denomina equipamiento al conjunto de construcciones e instalaciones que permiten asegurar a una población los servicios colectivos de los que tiene necesidad. Se pueden distinguir dosgrandestipos de equipamiento: los que se encargan de la infraestructura (calles $y$ aparcamientos, suministro eléctrico y energético, transporte y comunicaciones, diversas redes de canalización, parquesy jardines $y$ tratamiento de desechos) y los que se encargan de la superestructura (equipamientos administrativos, comerciales, culturales, sanitarios, sociales, deportivos, etc.). Para efectos del análisis que en este aparte

territarios 36

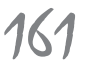


$\Leftarrow$

pretendemos hemos utilizado la categoría de servicios públicos como un concepto aparte para una mayor comprensión de los elementos desde los cuales se erige el discurso modernizante de la ciudad en el período que va de 1914 a 1948.

${ }^{3}$ Hygeia es el modelo de ciudad utópica propuesta por Benjamin W. Richardson, médico inglés especialmente preocupado por la bigiene de las ciudades. Su obra, titulada Hygeia, a City of Health, fue publicada en Londres en 1876. Fue concebida en principio como un estudio de la elevada mortalidad en las ciudades industriales con una higiene deplorable.

territarias 36 y El Universal, representaron la voz de los silenciados y el contra discurso presente en los documentos oficiales como El Diario Oficial, Los Anales del Concejo Municipal de Cartagena, La Gaceta del Departamento de Bolivar y los álbumes patrocinados por las elites y autoridades locales en donde se estampaba la bella imagen de la ciudad. En perspectiva historiográfica lo que se pretende es una historia desde abajo.

El texto se divide en tres partes. La primera aborda el tema de la higienización y la medicina social en la ciudad; la segunda hace referencia a los servicios públicos, agua, planta eléctrica y aseo y la tercera se ocupa de reseñar la adquisición de equipamiento urbano que, inicialmente, tuvo como propósito la recuperación del puerto, pero posteriormente estuvo al servicio de la diversificación económica.

\section{Higienización y medicina social: Cartagena la hygeia ${ }^{3}$ del Caribe}

La medicina urbana, como forma de la medicina social, nace con la medicina moderna científica. El objeto de esta medicina urbana, según Casas, no va a ser el individuo como cuerpo, sino el cuerpo social de la ciudad, es decir, el conjunto de espacios

Figura 1. Plano de la ciudad de 1915, elaborado por Pearson \& Son LTD

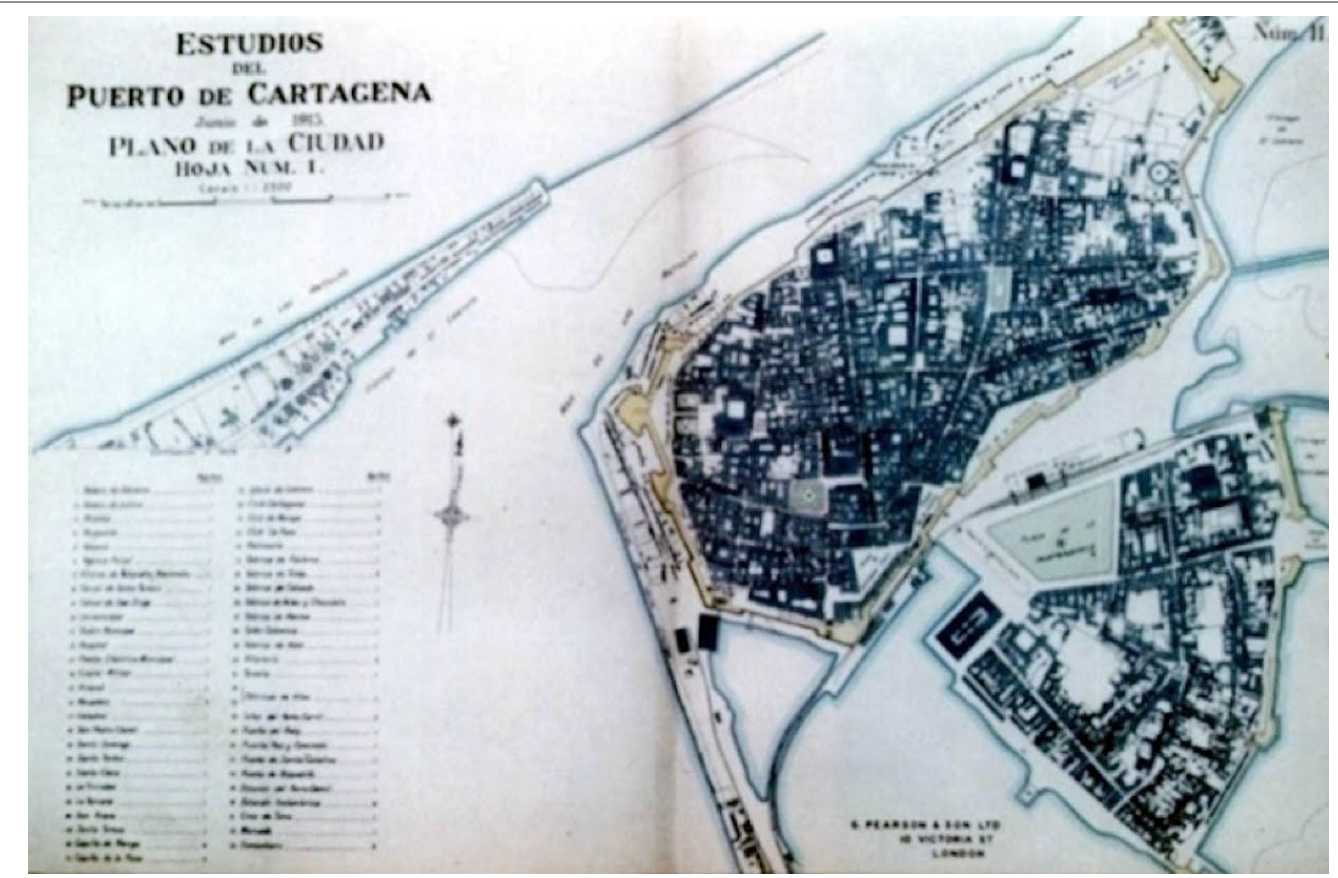

Fuente: Zabaleta, 2012, p.69 
y relaciones en los que se ve inmerso el citadino (Casas, 1996). De allí que la política de higienización sea regulada por el Estado y se oriente a garantizar la salubridad de los lugares públicos — cementerios, mataderos, basureros, ordeños y plaza de mercado-, el control de la circulación del aire y el agua y la organización técnica del acueducto y el alcantarillado. La modernidad y la modernización, como discursos apropiados por las autoridades locales y nacionales, pretenderán introducirse en el ámbito nacional y local a través de las acciones de higiene pública que, en el caso de Cartagena, proponen tanto el Plan Pearson como el Plano Regulador.

Precisamente una de las prioridades, tanto de las autoridades locales como nacionales, fue lograr la total higienización de Cartagena, en aras de hacer de ésta un puerto marítimo seguro y confiable. Cabe aclarar que mucho antes de la implementación del Plan Pearson existía la preocupación por las condiciones de salubridad de la urbe, puesto que estas se alejaban sustancialmente de lo dispuesto en la convección de Washington de $1905^{4}$ y con ello se corría el riesgo de quedar por fuera de las redes de intercambio que en pocos años inauguraría la apertura del canal de Panamá. Esta tendencia fue recurrente en el ámbito americano y en la Cuarta Convención Sanitaria Panamericana, celebrada en San José de Costa Rica en 1909, el tema se debatió como un problema de salud que las naciones participantes de la convención deberían atender recurriendo a:
La vacunación obligatoria contra la viruela; las campañas antipalúdica y antituberculosa, la centralización de la legislación sanitaria nacional; el impulso al estudio de las enfermedades tropicales para darles base científica y mayor auge a la parasitología y a la anatomía patológica; el establecimiento de laboratorios en los puertos no sólo para diagnósticos sino para hacer investigaciones originales en medicina tropical y patología general siguiendo las orientaciones que las autoridades sanitarias juzgaran adecuadas. (Estrella, 1995, p. 3)

En consecuencia con estos lineamientos el gobierno nacional, en 1913, promulga la Ley 33 , por la cual se organiza la Higiene Nacional pública y privada. En el artículo tercero de dicha Ley, para el caso de los puertos, se establece que:

En los puertos fluviales o marítimos en dónde sólo hubiere un médico, este, en asocio del Alcalde o la autoridad superior del lugar, y de un ciudadano o dos de los más ilustrados de la comarca o circunscripción, constituirán la junta de Salubridad del puerto, y promulgará y hará efectuar las medidas de aislamiento, cuarentena, lazaretos, desinfección, etc., de las personas, inmuebles y lugares contaminados. Todo de acuerdo con las instrucciones y preceptos establecidos por el consejo superior de sanidad. A quien se tendrá al corriente de cuanto ocurra y sea de interés en el interior de las poblaciones, durante la invasión y curso de la epidemia. (Gaceta Departamental de Bolívar, 1914, p. 1033)
${ }^{4}$ El 14 de octubre de 1905, durante la II Convención Sanitaria Internacional, se aprueba el Primer Código Sanitario Panamericano, con el propósito de codificar los procedimientos de sanidad internacional, particularmente en el control de la fiebre amarilla, basadas en las medidas ejecutadas en Cuba, la zona del Canal de Panamá y México. territarias 36

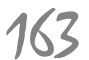


${ }^{5}$ Este articulo de prensa, titulado "por Cartagena. Saneamiento de la ciudad", se expresa lo siguiente: "en ediciones anteriores de este diario nos hemos ocupados ya, como interés en las conveniencias que traería Cartagena la demolición de todo este lienzo de murallas comprendido entre las Bocas del Puente y la Puerta de Santa Catalina, como medida de higiene y para ampliación y embellecimiento de la ciudad" (El Porvenir, 1914)

\section{territarios 36} 164
Tanto era el interés por el tema de la higiene y la salubridad en la Cartagena de inicios del siglo XX que durante mucho tiempo la prensa local reiteró sus constantes llamados de atención al respecto. Además de ciertas prácticas de los sectores pobres de la ciudad, consideraban - los articulistas - que las murallas eran la causa del estado anti-higiénico en que se encontraba la urbe ${ }^{5}$ (El Porvenir, 1914). Frente a estas reclamaciones las autoridades adoptaron medidas como la demolición de ciertos tramos del cordón amurallado, para de esta manera oxigenar la ciudad pues las fortificaciones "asfixiaban" a los habitantes del intramuros y mantenían un sopor que limitaba el crecimiento y progreso de la ciudad. Al respecto, el historiador Lemaitre, parafraseando a José Urueta, manifestaba que: "[...] los cartageneros habían realizado un sueño largamente acariciado: aislarse del cerco asfixiante de las viejas murallas, que los oprimían, más que física, psicológicamente" (1983, p.472). La disposición se complementó con el desalojo de los barrios Pekín, Pueblo Nuevo y Boquetillo, adyacentes a las murallas y símbolos de la Cartagena "pre-moderna y anti-higiénica".

Contrastaban las imputaciones de la prensa local sobre la problemática de la higiene en la ciudad, recurrentes durante las tres primeras décadas del siglo XX, con el discurso de La Sociedad de Medicina y Ciencias Naturales de Bolívar que, fundamentada en los postulados científicos de Pasteur, va a reclamar su competencia científica como autoridad reguladora del orden urbano.

La aparición de la figura del médico-higienista en Colombia tiene que ver con la de estas sociedades, pues ellas serían los cuerpos consultivos del estado para los asuntos de higiene y salubridad. Ser médico higienista era desempeñar una nueva función social en ejercicio público de la medicina dentro de una institución que era el "cuerpo médico de la ciudad". (Casas, 1996, p. 81)

Este doble posicionamiento, científico y político, le permitirá a la comunidad médica sustentar la imagen de una ciudad salubre. Las afirmaciones del médico Manuel Pájaro, al respecto, son muy ilustrativas:

Construyeron, los colonizadores, grandes cisternas públicas en las murallas y castillos de la histórica ciudad para el servicio especial del ejército. En gran número de casas existen también aljibes, más o menos capaces, que recogen las aguas de lluvia que se conservan más o menos bien aireadas y bajo la influencia depuradora del calor solar directo o reflejo. Hay además en cada casa, grande o pequeña, uno, dos o tres pozos de agua procedente de excavaciones y filtraciones. Todo esto según un antiguo sistema español que ha prestado y presta a la población incalculables beneficios en el ramo de aguas. Las de aljibe se han considerado potables y en este concepto se las ha venido usando sin graves reparos de la higiene y sin daño apreciable para la salubridad pública. (Casas, 1996, p. 81)

Fabricio Fabián Valdemar Villegas 
Sin embargo, la imagen de una Cartagena salubre presente en el discurso de los médicos higienistas fue confrontada por la pragmática de los ingenieros civiles de la época, como Ricardo Arango, quien comparó las condiciones higiénicas de ciudad de Panamá y Cartagena, concluyendo que ni la una ni la otra poseían sistemas sanitarios adecuados. En el debate entre médicos e ingenieros, finalmente, se impuso el discurso médico ante la técnica. A ello se debe que la ciudad, durante los tres primeros decenios del siglo $\mathrm{XX}$, no contara con circuitos de agua, lo que hizo de la higiene y la salubridad en la urbe una utopía, que se explayaba en la retórica de los galenos y la clase dirigente.

Pese a los intentos de las autoridades por generar una imagen saludable de La Heroica, las quejas de la prensa mostraban el estado malsano en que se hallaba gran parte de la ciudad y, en especial, los lugares habitados por los desposeídos.

\section{Los barrios pobres de Cartagena}

En repetidas ocasiones la prensa hablada y escrita de Cartagena se ha (sic) ocupado de uno de los aspectos más deplorables de nuestra insensibilidad social. La gente pobre, hacinada en inmundas covachas, vive de milagro. Que el paludismo y la gastro-enteritis infantil sean endémicos en los barrio proletarios de Cartagena, no debe extrañarnos si con aní (sic) imparciales practicamos una visita de inspección a esos lugares donde la miseria y el dolor anidan.
En materia de viviendas, Cartagena es la ciudad de los contrastes. Tiene barrios residenciales suntuosos como manga y Bocagrande. Pero hay sectores macabros, al margen de toda actividad profiláctica. El mundo al Revés, en lo amador, en Canapote, en el barrio esponja hay casuchas de madera. Enormes cajones con una sola puerta a la calle. El techo es de zinc, a muy poca elevación del suelo. El infernal vaho caliginoso del medio día hace el ambiente irrespirable. Ninguna de esas "viviendas" tiene servicio sanitario. Y barrios hay donde los gallinazos, las aves de corral y los cerdos reemplazan a las letrinas. (El Fígaro, 1945, p. 7)

La pretendida higienización, como muchos otros ideales, para hacer de Cartagena una urbe modernizada fue precaria, tanto que el mismo discurso profiláctico, una y otra vez, fue instrumentalizado por las elites y las autoridades locales y nacionales, en función de sus intereses. El ejemplo más relevante de esta práctica, entrada la segunda mitad del siglo XX, fue el uso que se hizo del estereotipo creado alrededor de Chambacú y sus habitantes. Este simbólico sector de la ciudad, como en otrora el corregimiento de Pekín, representaba el contra-ejemplo de la modernización. En el imaginario de la ciudad de los años 60, Chambacú no sólo era un lugar insalubre también era un espacio de miserables, violentos, inmorales, drogadictos y promiscuos que había que limpiar (figura 2).

Ni el Plan Pearson, ni el Plano Regulador lograron generar las condiciones higiénicas que garantizaran la plena 
salubridad de la ciudad de Cartagena y sus habitantes. Por el contrario, los consecuentes desalojos que estos provocaron multiplicaron los escenarios insalubres de la ciudad, puesto que los barrios bajos, hacia donde se desplazó la masa poblacional desarraigada, adolecían del equipamiento necesario para vivir saludablemente. A lo anterior se adicionaba el ambiente de las viviendas de los "nuevos barrios" que era, y sigue siendo, sumamente frágil y vulnerable ante las amenazas de morbos tropicales. Lo que se observa, entonces, es que el discurso modernizante de las elites, expresado a través de la retórica de la higienización, lo que pretendía, en últimas, era recuperar ciertos espacios - el suelo- estratégicos para viabilizar sus intereses de orden económico. Con el destierro de Pekín, Pueblo Nuevo, Boquetillo y Chambacú se saneó el territorio pero en los rostros de los pobres se exteriorizaba la inmundicia de la ciudad.

\section{Servicios públicos: acueducto, planta eléctrica y basuras}

Con todo y que Cartagena de Indias fue una de las primeras ciudades que a nivel nacional experimentó la operación de servicios públicos - agua y electricidad-por particulares (Casas, 1996, pp. 80-89), la cobertura y calidad de los mismos fue in-

Figura 2. Barrio Chambacú

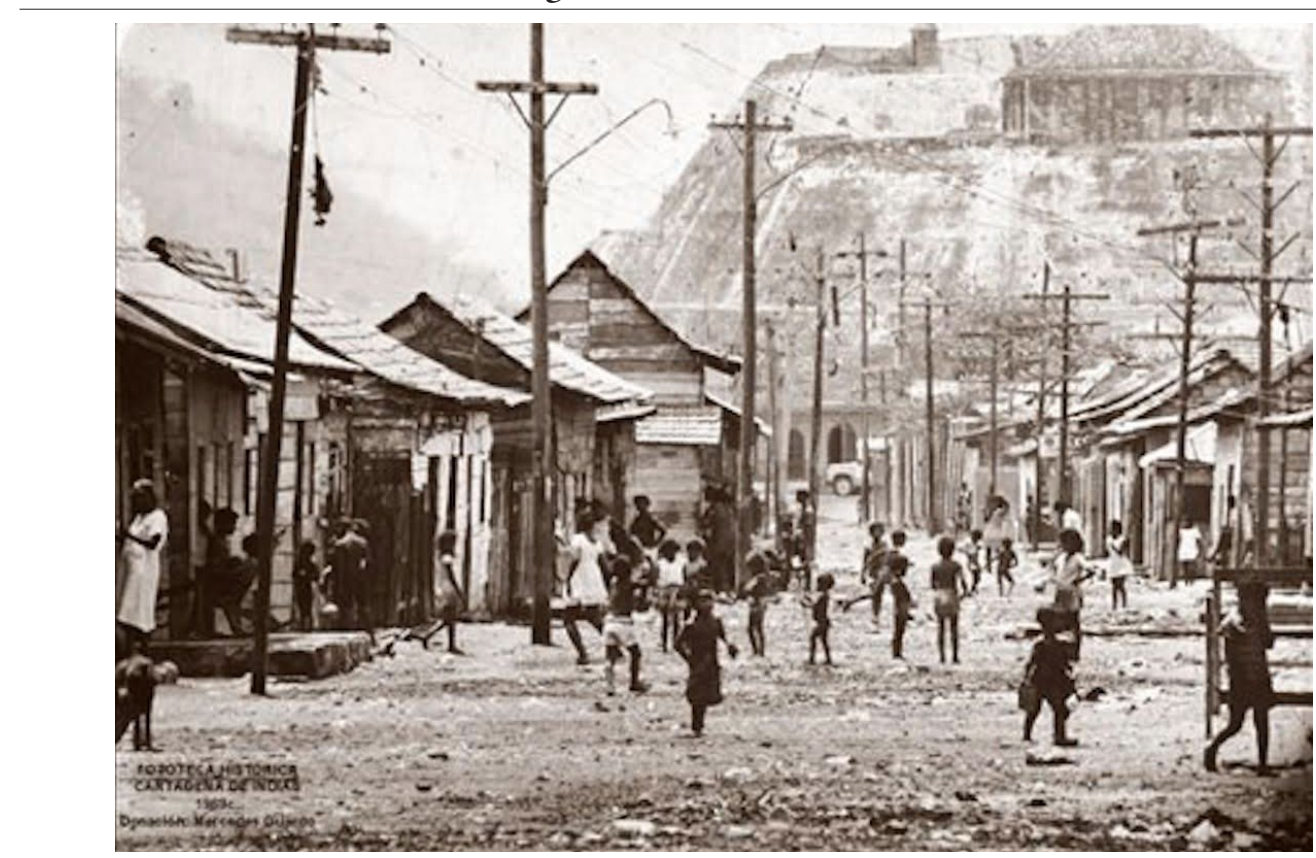

Fuente: Archivo fototeca histórica de Cartagena. 
suficiente. Al respecto, Varela considera que "los esfuerzos de configuración de un sistema de acueducto moderno, que se concretaron en el proyecto de Matute en 1904 solo lograron copar a las capas más privilegiadas de la sociedad cartagenera, dado que éste fue un servicio altamente mercantilizado, que excluyó a la mayor parte de la población de la ciudad" (2007, pp. 209-255). Los servicios de aseo y recolección de basuras, al igual que el alcantarillado, fueron prácticamente inexistentes durante la primera mitad del siglo XX, realidad que reforzaría el panorama de insalubridad que debió enfrentar la urbe y alimentó la percepción de caos de ciertos actores sociales de la capital del departamento de Bolívar.

\section{Acueducto}

Un anhelo de los cartageneros de principios del siglo XX fue contar con el servicio de agua potable. En la opinión cartagenera existía la convicción que con el suministro de agua en condiciones higiénicas, además de garantizarse la salubridad, le daría a la urbe el estatus de Ciudad Moderna. Históricamente, en Cartagena el agua para el consumo humano se obtenía de los aljibes construidos en cal o metal en donde, a lo largo del año, se depositaban la aguas lluvia. No obstante, con el advenimiento de la medicina social, se comprendió que la causa de muchas de las enfermedades endémicas provenía de las aguas estancadas. Es por ello que, desde finales del siglo XIX, las autoridades de la ciudad, encargadas de la salubridad y la higiene pública, van a insistir en la construcción de un acueducto ${ }^{6}$ que logre cubrir la demanda de este servicio.

Para cuando se implementa el Plan Pearson, Cartagena cuenta con una empresa de acueducto llamada Compañía del Acueducto de Cartagena, dirigida por el inglés William Eduard Hughes Dickin, siendo uno de sus propósitos contribuir al saneamiento de la ciudad y, por ende, a la modernización de la misma. Pero, como ocurrió con sus antecesoras, la compañía no logró satisfacer las expectativas de las autoridades. La opinión pública que observaba como un elemento modernizador, tal como era el agua potable, cada vez parecía más lejos de alcanzarse. Un artículo de prensa de 1916 sostenía que:

Entre los grandes problemas urbanos que tiene Cartagena por resolver y que al juzgar por lo que se ve, será muy tardíamente definido, continúa figurando a la cabeza de todos, el de la provisión de agua potable... La falta de agua detuvo el crecimiento de Cartagena. Barrios excéntricos como el de Manga que en un principio tuvieron un desarrollo que iba a saltos asombrosos, han quedado paralizados desde que se hizo difícil, casi imposible, la consecución de agua a los pobladores de escasos recursos... El barrio Manga, así como los demás barrios de fuera del recinto amurallado, se ven abandonados y todo hace temer una nueva aglomeración en los barrios centrales, perjudicial no sólo para el desarrollo de Cartagena, sino aún para la vida misma de sus habitantes. (Casas, 1994, p. 86)
${ }^{6}$ El primer acueducto de la ciudad de Cartagena se conoció como el acueducto Russel yentró en funcionamiento en 1892. territarias 36

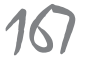


Reclamaciones similares a lo largo de los primeros treinta años de la centuria pasada, aparecerán reiteradamente en la prensa local. En un artículo del diario de la tarde, Unión Comercial, se elogia la iniciativa adoptada por su rival, El Porvenir, para enviar un telegrama al Congreso de la República en donde se propone "prolongar el actual acueducto hasta el río Magdalena, con el objeto que toda la población pueda proveerse de agua potable" (La Unión Comercial, 1915, p. 1). A la falta de agua se le atribuía el estancamiento de la ciudad. Las distintas compañías inglesas que operaron el suministro del preciado líquido veían truncados sus esfuerzos por obtener, en cantidades suficientes y en condiciones de calidad, tan vital elemento. Las disposiciones administrativas y las repetidas querellas de orden contractual poco fue lo que contribuyeron a la superación de esta insuficiencia en la prestación del servicio de agua potable. Sólo hasta 1938, con la inauguración del acueducto de Gambote (Calvo \& Meisel, 1999), la ciudad pudo disfrutar de la prestación sostenida de tan vital fluido.

No obstante, después de inaugurado el acueducto del Canal del Dique, se seguían presentando fallas en el servicio. Por ejemplo, en 1948, año en que se propone el Plano Regulador de la ciudad, la empresa de servicios públicos que administraba el acueducto manifestaba un déficit en la existencia de cloro con el que se potabilizaba el agua. En un diario de la época se hacía saber a la opinión pública de la ciudad sobre tal asunto:
Hace pocos días informamos sobre la solución provisional que la junta de control de cambios, de Bogotá, había dado al problema de la provisión de cloro para la empresa del acueducto de esta ciudad, mediante la autorización de una licencia para importar 12 cilindros de dicho artículo con la advertencia hecha a la junta de las empresas públicas que se trataba del último permiso en ese sentido, pues en concepto de aquella entidad había suficiente cloro en el país. (El Universal, 1948, p. 2)

A los problemas de optimización de la prestación del servicio de agua potable se agregaría el de cobertura. Cuando se instaló el acueducto de Gambote, la ciudad contaba con una población de 84937 almas y, para 1951, los habitantes de Cartagena eran 128877 (Meisel, 1999). A propósito de este desajuste entre crecimiento demográfico y estancamiento de la cobertura de los servicios públicos un artículo de la prensa en 1948 advertía lo siguiente:

Compárense las estadísticas de población de esta ciudad, o sea el proceso vegetativo que ha tenido el aumento de los habitantes en un periodo de quince a veinte años, y se podrá ver con entera exactitud que el municipio no ha logrado darle impulso a sus servicios públicos más importantes y fundamentales, en proporción a las reglas demográficas que señalan los expertos en estas materias. Se observa, por el contrario, que no se ha contado con los factores más esenciales que determinan el progreso en las ciudades de

Fabricio Fabián Valdemar Villegas 
cien mil habitantes como la nuestra. Vamos siempre a la zaga. (El Universal, 1948, p. 5)

En atención a este desarreglo entre el aumento poblacional y la insuficiente provisión de agua potable, el Concejo Municipal de Cartagena, en 1948, acuerda lo siguiente:

[...] la alcaldía de distrito procederá a hacer ante la Compañía de Servicios Públicos de Cartagena las gestiones necesarias para que la tubería moderna sea prolongada de las inmediaciones del Hotel Caribe, hasta donde llega en la actualidad, hasta el sitio del paraje llamado "El Laguito" final del barrio de Boca Grande, $[\ldots]$, a fin de que los habitantes de los caseríos de Tierra Bomba y Caño de Loro (sano), puedan llegar hasta allí a abastecerse de agua. E igualmente la Alcaldía dictara las medidas del caso para reparar convenientemente el pozo colonial de Tierra Bomba de donde venía proveyéndose la población [...], puesto en consideración es aprobado y adoptado; $[. .$.$] Construcción de amplios$ pozos artesianos en la población de Santana y el caserío de Ararca. (Anales del Concejo Municipal de Cartagena, 1947, pp. 13-14)

Pese al interés del concejo municipal por extender el alcance de la tubería del acueducto hasta el final de la zona norte de la ciudad y el esmero por sanear algunos pozos de recolección de "caseríos" que formaban parte de la división político administrativa del distrito lo que se logra apreciar es que el nuevo sistema de acueducto es insuficiente e ineficiente. $\mathrm{Si}$ bien la ciudad logró por fin, antes de finalizar la primera mitad del siglo pasado, solucionar el problema de abastecimiento de agua y la prestación del servicio pasó a manos del Municipio, lo cierto es que las condiciones del mismo, en el periodo finisecular, seguían siendo precarias. Es más, en muchos barrios de la zona norte y suroriental, construidos entre finales del siglo XIX y principios del siglo XX, este servicio no existía (Calvo et al., 1999) y el agua llegaba a los hogares sobre los hombros de los aguadores o en aguaderas a lomo de burro.

Las deficiencias en la prestación del servicio de agua potable, en cantidades suficientes y con la calidad necesaria, evidenciadas en las fuentes primarias, permiten inferir que la política pública en los asuntos de servicios públicos fue de carácter coyuntural e inmediatista. Durante gran parte del siglo pasado la ciudad careció de un plan maestro de acueducto que respondiera a su dinámica de crecimiento demográfico y a los estándares de calidad.

\section{Planta eléctrica}

En 1891 entró en funcionamiento la primera planta eléctrica de Cartagena que sería remplazada por una segunda en 1896 (Meisel, 1999). A pesar que el servicio de energía eléctrica se prestaba hacía más de veinte años, para 1915 las condiciones del mismo son pésimas. La planta no funcionaba durante todo el día y era insuficiente para garantizar el alumbrado público. La situación se explica por los altos costos territarias 36

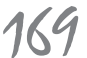


del mantenimiento de las máquinas que el municipio, administrador de la planta, se veía en dificultades de sufragar, debido a que los ingresos del ente gubernamental eran exiguos. Frente a esto algunos sectores de la oposición, de tendencia económica liberal, proponían la privatización de la planta, entendiendo que, si se alimentaba la administración de la misma con capital particular, seguramente el servicio que prestaba a la ciudad mejoraría y con ello se daba un paso más hacia el progreso de la urbe. La Unión Comercial, uno de los diarios que más insistía en aquellas medidas, en un aparte de uno de sus artículos referidos a la situación de la planta, expresaba:

La planta eléctrica es tal vez asunto que necesita, que requiere y que exige inmediato cuidado. Sabido es del público el estado en que se encuentran las maquinarias y especialmente las calderas de la planta. El uso permanente durante más de veinte y cinco años, las han puesto en un estado lamentables y estamos expuestos, según voz general, a que de un momento a otro volvamos al medio primitivo de alumbrado, sin contar que sería una vergüenza más grande, que para despejar las sombras de las vías públicas hallamos de recurrir a los antiestéticos faroles de antaño, que con su luz montesina inspiraban tristezas y dejaban muy poco que decir de la ciudad en donde nació Bolívar a la gloria. (La Unión Comercial, 1915, p. 2)

Más adelante, en el mismo documenterritarias 36 170
[...] sería de desearse que los municipales acordaran su administración o cedieran los permisos convenientes para que alguna empresa particular - netamente colombianala establezcan en debida forma. La planta eléctrica siempre ha sido costosa para el Municipio, pues si bien, últimamente aparece como si resultara de balde el alumbrado público, es porque no se ha tenido en cuenta el consecuente desgate de las maquinarias, que cuesta dinero.

Una empresa particular, con capital suficiente para dotar a Cartagena de una planta eléctrica moderna, con capacidad suficiente, para dotarla de la luz suficiente, que pueda producir energía durante el día..., sería un adelanto indudable y la ciudad lo requiere. (La Unión Comercial, 1915, p. 2)

Continúa el documento llamando la atención sobre los proyectos que requiere la ciudad, particularmente en lo referido al alumbrado público, y exhortando a los honorables concejales del municipio para que den el visto bueno a las propuestas de privatización de la planta eléctrica.

En 1923, ante la insistencia de los sectores políticos partidarios de la privatización quienes reiteradamente argumentaban la ineficiencia de la planta, la administración de esta se entrega a la empresa inglesa Cartagena-Colombia Waterworks Ltd (Viloria, 2011). Sin embargo, el monopolio de la Waterworks, que ahora manejaba tanto el acueducto como la planta eléctrica, no solucionó los problemas de ineficiencia de ésta última, sobre todo en los barrios pobres 
de la ciudad, cuyos habitantes carecían de los ingresos suficientes para pagar un servicio que se había comercializado. Un artículo de la prensa local de 1929 es evidencia de lo poco que había cambiado el oficio prestado por la planta:

Vecinos de los barrios costaneros de Pekín, Pueblo Nuevo y Boquetillo, se quejan del deficiente alumbrado eléctrico de sus calles debido, según parece, a que casi todos los bombillos tienen los filamentos quemados. Desean y ello es de esperarlo de los señores de la gerencia de la Planta eléctrica, que tal irregularidad será corregida. (La Patria, 1929, p. 3)

En 1928 el gobierno nacional había promulgado la Ley 113 de energía eléctrica que declaró de utilidad pública el aprovechamiento de la fuerza hidráulica y autorizaba la inclusión de partidas en el Presupuesto Nacional. Es por ello que, en 1931, bajo la modalidad de empresa integrada, surge la empresa de servicios públicos de Cartagena y se municipaliza la prestación de los servicios básicos (Varela, 2007). Cabe destacar que la municipalización en la prestación de los servicios públicos fue una tendencia nacional en los años treinta del siglo XX ante la incapacidad de la empresa privada por mantener los ritmos de inversión en el sector, dado el sostenido crecimiento de la demanda (Fainboim \& Rodríguez, 2000; Tabarquino, 2011) resultado del acelerado crecimiento demográfico que experimenta la ciudad de Cartagena. No obstante, este modelo de financiación y administración de los servicios básicos, denominado descentralizado, muy pronto evidenció sus debilidades. Ante esta situación de orden local y nacional, el modelo descentralizado, en los años 30, daría paso a la intervención estatal por lo que en 1938 se crea un Departamento de Empresas de Servicio Público y se define con mayor precisión las relaciones fiscales intergubernamentales en relación con la financiación del servicio de energía eléctrica (Tabarquino, 2011, p. 1) . $^{7}$

En el desarrollo posterior de estos sistemas (municipalización de los servicios públicos) se pueden distinguir al menos tres períodos: el primero, que va de 1936 a 1950, marcado por la creación y operación del Fondo de Fomento Municipal, evento que significó el cambio a un modelo sostenido de financiación con recursos de la nación; el segundo período, que va de 1950 a 1986, caracterizado por el fortalecimiento de la participación nacional, que se extiende a la administración y operación de los sistemas a través del Insfopal y el último, que arranca con la quiebra y liquidación del Insfopal, determinado por los procesos de acentuación de la descentralización política y fiscal, por un mayor énfasis en la aplicación de principios comerciales en la operación de los sistemas y los primeros signos de participación privada.

Los esfuerzos del gobierno nacional en materia de regulación sobre el suministro, financiación y administración del servicio de energía eléctrica, para el caso de la ciudad de Cartagena, surtió pocos efectos positivos. Al final de la primera
${ }^{7}$ La Ley 80 crea el Instituto Nacional de Aprovechamiento de Aguas y Fomento Eléctrico, primer instituto descentralizado del sector a nivel nacional. territarias 36

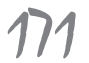


mitad del siglo XX aún persistían los viejos males que habían caracterizado a la otrora planta eléctrica. A propósito de esto, en un ejemplar de El Fígaro de 1945 hacía el siguiente llamado de atención al gerente de la compañía de servicios públicos de la ciudad:

Varios habituales concurrentes al Parque del Centenario nos informan que en la noche del domingo pasado la Banda de Música dirigida por el maestro Puello no pudo tocar la retreta acostumbrada debido a un daño en la conexión eléctrica que sólo fue provisionalmente arreglado después de las ocho y media de la noche. En semana anterior también había ocurrido igual accidente que privó a la numerosa concurrencia de un rato de ameno solaz.

Muy atentamente, pues, nos permitimos pedir al señor Gerente de la Compañía de servicios Públicos se sirva ordenar la composición definitiva del mal que apuntamos, a fin de que no sean suspendidas las retretas dominicales en el Parque del Centenario, a las cuales asiste una numerosa concurrencia. (El Fígaro, 1945, p.2)

Ante el lamentable estado del suministro eléctrico, el Concejo Municipal, en 1947, adoptó el acuerdo para el ensanchamiento de la_planta eléctrica, proyecto que se adelantaría con la inversión de dineros del municipio, con el fin de obtener una mayor cobertura, de tal manera que se posibilitara hacer de la ciudad un sitio más atractivo para el establecimiento de industrias y empresas pues, en ocasiones anteriores, se habían perdido oportunidades de asentamiento de estos negocios por falta de una correcta prestación del servicio. Otro objetivo era mejorar el bombeo del acueducto, lo que se traduciría en una mejor y mayor prestación de éste servicio a la ciudadanía. Finalmente, dicho ensanchamiento facilitaría la adecuación de escenarios públicos como el estadio Once de Noviembre que en ese momento se estaba construyendo.

La junta administradora de la Empresas Públicas Municipales, gestionara con el Departamento de Bolívar el cumplimiento de la Ordenanza número 126 de 1947, sobre ensanchamiento de la Planta Eléctrica de Cartagena. Puesto en consideración es aprobado y adoptado; Artículo $6^{\circ}$. Declárese de GRAVE NECESIDAD PÚBLICA, el ensanche y mejoramiento de la Planta de Eléctrica Municipal, para el progreso industrial de Cartagena, hoy estancado lamentablemente con perjuicio para la ciudad. Puesto en consideración, aprobado y adoptado. (Libro de Actas de los Anales del Concejo Municipal, 1948, p. 40)

Aunque el ensanchamiento de la planta eléctrica parecía ser uno de los caminos para que la ciudad superara su atraso, lo cierto es que las obras para tal propósito debieron esperar. Las pujas políticas y los trámites burocráticos que implicaba una empresa de tal magnitud se convirtieron en inconvenientes importantes. Otro de los obstáculos fue la dilación de la junta de las 
empresas públicas para decidir la adjudicación de las obras de ampliación, muy a pesar que existía un abanico de oferentes (El Universal, 1948). Los debates que suscitó el aplazamiento de tan requerida obra no se hicieron esperar al interior de la sociedad cartagenera. Adicionalmente, las trabas que imponía la oficina de control de cambio para la importación de insumos y repuestos, hacían que la ciudad, a mediados de la pasada centuria, se mantuviera a oscuras (El Universal, 1948).

Efectivamente, el suministro de energía eléctrica, con eficiencia y eficacia, fue una reclamación constante de los cartageneros de mediados de siglo. Los resultados de la encuesta que realizara el diario El Universal el 4 de junio de 1948 así lo dejan ver. La publicación consideraba que el mayor problema de la ciudad era el de la planta. Pero, además, esta problemática motivó las más serias reflexiones sobre el frágil equipamiento urbano de la ciudad. $\mathrm{Al}$ respecto, en un editorial de El Universal que versaba sobre los servicios públicos - energía eléctrica一, se deliberaba lo siguiente:

Hay que evitar los errores en q' (sic) se ha venido incurriendo de proyectar las obras de progreso con criterio muy limitado y estrecho de no tomar muy en cuenta el amplio desarrollo que ofrece la ciudad si se le impulsa eficazmente. De ahí ha surgido la poca o ninguna ventaja de nuestro adelanto urbano, comparado con el de otras ciudades colombianas. $Y$ de esas causas depende que se considere que esta urbe debe con- vertirse en un museo nacional, aislada del movimiento progresista del país. Tamaño absurdo se debe a que no queremos admitir el determinismo geográfico que señala a Cartagena como un futuro centro industrial de gran categoría y que podríamos realizarlo si abandonáramos esta mortal inercia y la miope visión de nuestros problemas locales. (El Universal, 1948, p. 2)

Para los analistas de entonces la ampliación de la planta eléctrica, como gran obra de infraestructura, no solo permitiría satisfacer las expectativas de los usuarios del servicio sino que, además, posibilitaría las condiciones necesarias para que la ciudad enfrentara los retos del futuro. Retos que tenían que ver con el crecimiento demográfico y la diversificación económica, sobre todo con la inserción de la ciudad en el sector industrial ${ }^{8}$. Recuérdese que una de las propuestas del Plano Regulador, bajo el modelo de la diversificación, fue hacer de Cartagena una ciudad industrial y para ello era preciso contar con el suficiente servicio de energía eléctrica que la hiciese atractiva para inversionistas, cuyos intereses se orientaran hacia la esfera de la transformación.

Pero ni el ensanchamiento de la planta eléctrica, ni la creación de la electrificadora de Bolívar en 1958 lograron solucionar los problemas de suministro de energía en Cartagena. A la elevada demanda del servicio, producto del sostenido incremento de la población, se sumará el requerimiento de la industria petroquímica de Mamonal que iniciará sus operaciones
${ }^{8}$ En Colombia, a partir de 1945, el modelo de sustitución de importaciones se acompañó de una politica definida de control a las importaciones, con un propósito industrialista, y de la aplicación de una serie de politicas de carácter sectorial que permitieron un acelerado y dinámico crecimiento del sector manufacturero. Con esto se pretendia crear las bases del andamiaje de la industria manufacturera. Entre ellas, la creación de Instituto de Fomento Industrial (IFI) en 1940 sería un elemento fundamental para el apoyo de la inversión y montaje de sectores industriales como la industria química, de caucho y metalúrgica, entre otros.

tersitarias 36

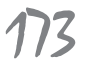


${ }^{9}$ Esta situación era común a todas las grandes urbes del pais durante la cronología señalada.

${ }^{10}$ Es sólo a partir de 1975 que el pais cuenta con una seria y sostenida normatividad en el asunto del aseo público. En 1975 el INSFO$P A L$ deja sus funciones que eran financiar, planificar, diseñar, construir, operar, mantener yadministrar los servicios públicos en los municipios y se encarga de fijar las politicas delgobierno referentes a los acueductos, alcantarillados, mataderos, aseo público y plazas de mercado (Decreto 2804).

territarios 36 174 al final de los años 50, con la instalación en esta zona de la refinería por parte de la International Petroleum Colombia Ltd. (Intercol) en 1957 (Báez \& Calvo, 1999). Tan precario era este servicio que, para los años 50, el consumo de energía eléctrica de uso no industrial no alcanzaba los 100 kilovatios-hora por habitante (Calvo et al., 1999). La energía eléctrica y la "luz", en la Cartagena de la primera mitad del siglo $\mathrm{XX}$, era tan pobre como la ciudad.

\section{Basuras}

El manejo de la basura en la ciudad de Cartagena durante la mayor parte del siglo XX constituyó uno de los principales retos urbanos que debió afrontar la autoridad local (Gaceta Municipal, 1927). Por muchos decenios la ciudad careció de un sistema de recolección, deposición y tratamiento de los desechos. A los ojos de muchos observadores esta realidad no sólo daba la apariencia de una ciudad sucia sino que, además, era una manifestación de la ingobernabilidad y del desorden (El Porvenir, 1903).

En la ciudad, desde los inicios del siglo XVII, existía un basurero público frente a la Calle del Tejadillo justo donde, a finales del siglo XIX se instaló el corregimiento de Boquetillo. Sin embargo, entrado el siglo XX, continuaba la práctica de tirar la basura sobre la franja costera adyacente a las murallas, sin más tratamiento que su incineración indiscriminada. Pese a esto — así lo dejan ver las pocas fuentes al respecto- la ciudad se privó de una política pública cuyo objeto fuese la administración de las basuras.

La higienización y salubridad de Cartagena fue uno de los ejes principales del Plan Pearson. Curiosamente, este plan no contempló las obras de equipamiento urbano que le permitieran a la ciudad contar con una fórmula para la manipulación de las basuras, pese a que no se contaba con un sistema de disposición de los desechos. Para la segunda década del siglo XX los basureros se habían multiplicado, al igual que los malestares que agobiaban a la población como consecuencia de la falta de un tratamiento adecuado a las basuras. A la ausencia de una regulación en ésta materia se sumaban unas prácticas culturales que poco contribuían a la superación de tan sentido problema con el que tenían que convivir los cartageneros de entonces (El Porvenir, 1914, pp. 2-3).

Para los años 20 y 30 son muy pocas las mejoras que se observan con relación al tema de aseo y basuras. La disposición final de los residuos sólidos se seguía haciendo en basureros a cielo abierto o en los cuerpos de agua ${ }^{9}$. Ni en la ciudad ni el país existían las condiciones técnicas (León, 2006) y la legislación ${ }^{10}$ necesaria para que el tratamiento dado a las basuras fuera diferente. Cabe agregar que esta problemática, para la época, era un asunto de la estética urbana y "no representaba por lo tanto un riesgo ambiental" (León, 2006, p.141).

Para 1945 la ciudad seguía presentando un cuadro de desaseo, no obstante que para éste momento ya existía la dirección 
de aseo (El Fígaro, 1945). Algunas iniciativas de aseo público fueron agenciadas por sectores de la sociedad civil cartagenera que observaban con estupor como algunos lugares emblemáticos de la ciudad se convertían en basureros ante la ciega mirada de los gobernantes (El Fígaro, 1945). Esto se explica porque la ciudad no contaba con un lugar predeterminado para la disposición final de las basuras.

Para la década de los 50 y 60 el panorama antes descrito poco o nada cambiará. Las basuras se botaban en solares baldíos y, en el mejor de los casos, se quemaban. Muy a pesar de la percepción que tenían las autoridades locales sobre el asunto, en la práctica, las acciones para superar esta deficiencia fueron insuficientes a pesar del servicio de recolección y transporte de los residuos sólidos, prestado por las Empresas Públicas Municipales. La ciudad tendría que esperar hasta 1972 para contar con un basurero (Alcaldía de Cartagena, Programa de las Naciones Unidas para el Medio Ambiente, Establecimiento Público Ambiental de Cartagena \& Observatorio del Caribe Colombiano, 2009) ${ }^{11}$.

El problema de aseo, recolección y disposición final de los desechos sólidos fue de carácter estructural en Cartagena durante el siglo XX. Pero, además, fue un asunto que pocas preocupaciones generó siempre y cuando no atentara contra la bella imagen de la ciudad. Las acciones coyunturales para responder a ésta dificultad son la más clara expresión de la falta de una política pública que respondiera, con las exigencias del caso, a una problemática que aparentemente poco o nada incidía en la vida de los citadinos habitantes. Sin embargo, constituyó una de las mayores molestias de larga duración con la que ha tenido que convivir La Heroica que, una vez más, tendría que soportar un sitio pero, en esta ocasión, el cerco sería por cuenta de una legión conformada de montañas de basuras.

\section{Equipamiento urbano}

La necesidad de dotar a la ciudad de un equipamiento urbano atravesará tres momentos claramente distinguibles. El primero que pretenderá hacer de la ciudad el principal puerto marítimo del país; el segundo, es el periodo de transición que coincide con la expresión arquitectónica de igual denominación y el tercero, que corresponde al propósito de la diversificación económica, de la mano del funcionalismo arquitectónico. Si bien los tres períodos presentarán rasgos particulares, también es posible observar en ellos ciertos elementos comunes que permiten apreciar la continuidad de procesos de larga duración en la ciudad, como la exclusión social, o bien coyunturas, como los ciclos económicos de auge y rezago, que experimentó la urbe durante gran parte de la centuria pasada.

\section{A recuperar el puerto}

Para cuando se inicia la implementación del Plan Pearson la ciudad de Cartagena evidenciaba una crisis económica (La Unión Comercial, 1915). Aprieto que se explica
${ }^{11}$ Los residuos sólidos, como se les conoce técnicamente, se arrojaban en un predio en el barrio de Henequén, en donde funcionó un botadero a cielo abierto entre los años 1972 a 1993. El botadero operó sin ningún tipo de control técnico durante treinta y cinco años hasta que. en 1994 debido a una acción de tutela instaurada contra el Distrito, cesó su operación. territarias 36

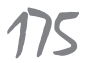


por su aislamiento de las rutas comerciales a través de las cuales el país logró su articulación al mercado mundial. Verbigracia, la ciudad no logró conectarse con el río Magdalena en condiciones que le permitieran competir con su vecina Barranquilla y abrirse camino hacia la prosperidad económica. A propósito de esto, un autor anónimo del diario de la tarde, La Unión Comercial, en 1915 llamaba la atención de las autoridades locales, por el abandono al que había sido condenado el proyecto de canalización del Dique en el que muchos empresarios como Juan Mainero y Truco veían el camino redentor de la ciudad ( $\mathrm{La}$ Unión Comercial, 1915). Para entonces el ferrocarril Cartagena-Calamar se convirtió en la esperanza de los cartageneros para participar del ejercicio de las exportaciones e importaciones. No obstante sus efectos en el escenario económico de Cartagena fueron intrascendentes. Es más, las utilidades producto de las operaciones del ferrocarril, en las tres primeras décadas del siglo XX, no se redistribuyeron en el presupuesto, ya que era manejado por una empresa privada (Calvo et al., 1999).

El rezago económico se traducirá, finalmente, en las limitadas posibilidades de renovación urbana. A la crisis de las finanzas se le sumarán la negligencia de las autoridades locales para enfrentar las necesidades de la ciudad y los trámites burocráticos del gobierno central para iniciar las obras proyectadas en el Plan Pearson. Obras como la reparación de calles, la construcción de un nuevo matadero, el mantenimiento del Parque del Cente- nario, la refacción de edificios públicos, entre otras, fueron motivo de halago o bien de exigencia reiterada por parte de la prensa local durante la segunda década del siglo XX.

Dos eran las razones que se exponían para solicitar con urgencia las obras de renovación urbana. Una era lograr el embellecimiento de la ciudad, a fin de darle la apariencia de una autentica urbe y otra - la fundamental - era conseguir la higienización del intramuros y, con ello, garantizar el saneamiento del puerto y su entorno. A manera de ejemplo transcribimos el siguiente comentario que apareció en una edición del diario Unión Comercial:

\section{Calle de las damas}

En la próxima semana, con la ayuda de la Dirección de Higiene, empezará la comisión sanitaria la composición de la calle mencionada arriba. Con loable esfuerzo y buena voluntad los encargados de velar por la salubridad pública están llevando a cabo esta obra meritoria.

Falta ahora que el Consejo Municipal, poniendo a un lado rencillas que solo conducen a perturbar la marcha administrativa del Distrito, dedique algunas horas -y algunos reales -en disponer que el saneamiento se efectué en toda la urbe, único medio de terminar con las epidemias que la azotan. (La Unión Comercial, 1915, p. 3)

En el periodo comprendido entre 1914 y 1922 la ciudad de Cartagena fue 
un escenario en el que las obras de renovación urbana fueron las grandes ausentes. La ilusión que despertó el Plan Pearson en materia de equipamiento y ensanchamiento se limitó a la macadamización de las calles del centro histórico, la reparación de edificios públicos y el encarecimiento del suelo residencial en el intramuros. La Gran Guerra agudizaría la recesión que se experimentó en la ciudad. Sus consecuencias sobre la soñada modernización no se hicieron esperar. Mientras tanto, las autoridades locales, a la sombra del infortunio, reposaban en su desidia.

Los grandes proyectos de infraestructura, asociados a la recuperación del puerto, llegarían entrados los años 20. En 1923 se inicia el dragado del Canal del Dique por parte de la Foundation Company, a quien la Junta de Limpieza y Canalización del Dique le encomendó la tarea mediante contrato público (Aguilera, 2006). Sin embargo, las obras de mayor impacto en la vida económica y social de la ciudad fueron realizadas por la ANDIAN, compañía que, en 1925, inició la construcción del oleoducto Barrancabermeja-Mamonal que entró a funcionar en 1926. Para finales de esta década la misma compañía canadiense propició la urbanización de Boca Grande.

Lo que se aprecia es que la preocupación por las magnas obras, de alguna manera, impidió la realización de las construcciones que los cartageneros requerían para afrontar la vida cotidiana. Pero, cuando estas se realizaban se circunscribían al centro histórico. Los barrios populares seguían marginados de la dinámica urbana (Diario de la Costa, 1927). Para 1929 Pekín, Pueblo Nuevo y Boquetillo (figuras 3 y 4), los barrios populares más representativos, como bien se ha anotado, seguían presentando el mismo aspecto que los había caracterizado desde sus orígenes (La Patria, 1929): seguían siendo "alojamientos ilegales” (Fuente, 1999, 233).

En los años 30, después que se incendió el muelle de la Machina en 1932, el gran logro para la ciudad en cuanto a infraestructura fue la inauguración del Terminal Marítimo de Manga en 1934 (figura 5 ). Otra obra fue la Avenida Santander cuya construcción se inició en 1939 pero que sería inaugurada en 1969. Para este mismo decenio se abre el aeródromo de Manzanillo y se inician los trabajos de construcción del Edificio Nacional, símbolo de la presencia del poder central en la ciudad (Gaceta del Departamento de Bolívar, 1939). Pero estas obras ni lograron el posicionamiento de Cartagena como el principal puerto marítimo del país, ni ofrecieron oportunidades de crecimiento económico que se tradujera en desarrollo urbano. Lo primero se explica porque, si bien el terminal marítimo de Manga impulsó el negocio de las exportaciones, el puerto de Cartagena a partir de 1930 sería superado por Barranquilla y por Buenaventura cuyo puerto entró en operaciones ese año (Calvo et al., 1999). Sumado a lo anterior podemos anotar que, agenciadas en su mayoría por el gobierno central, la totalidad de estas construcciones fueron ejecutadas y operadas por empresas privadas extranjeras. territarias 36

177 


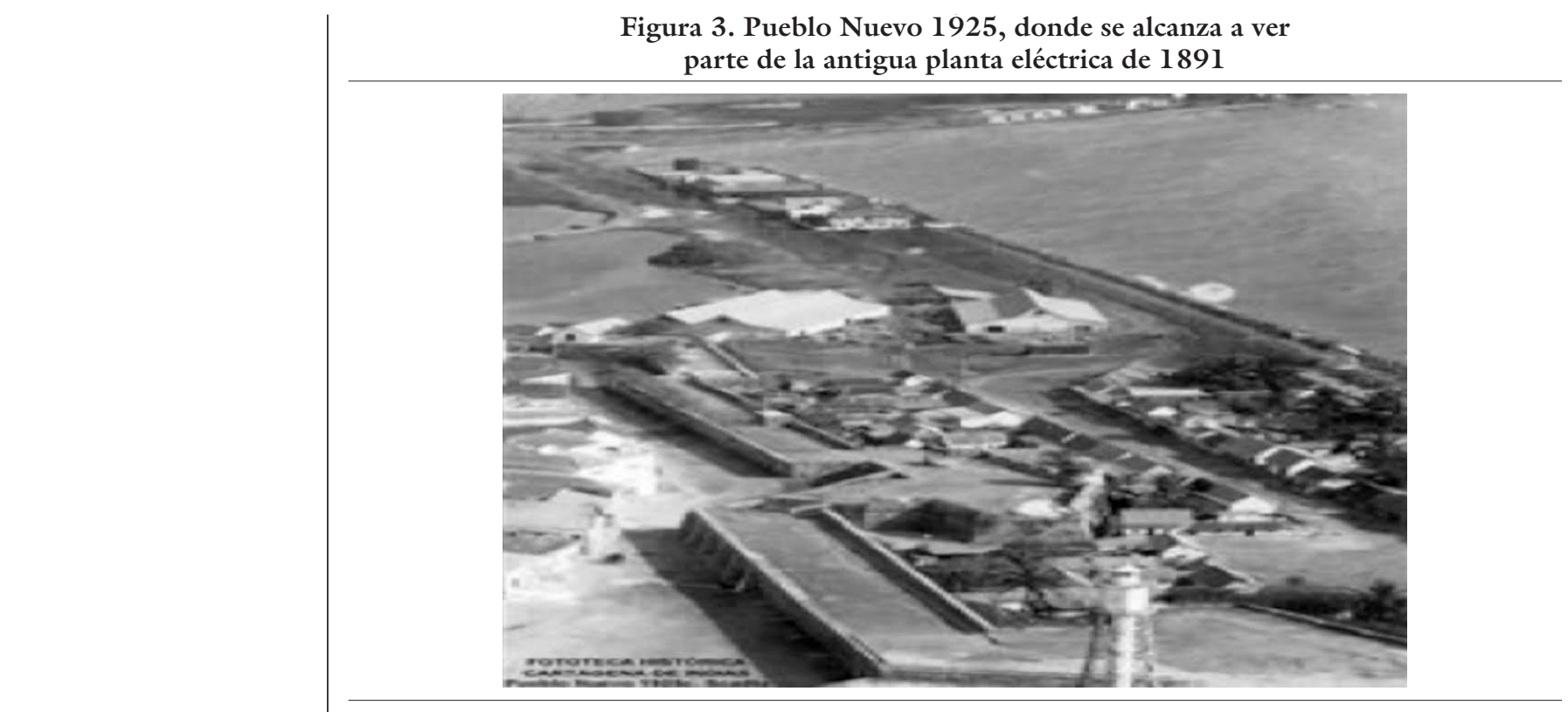

Fuente: Archivo fototeca histórica de Cartagena.

Figura 4. Vista aérea de Cartagena, hacia la bahía con los barrios Pueblo Nuevo, Pekín y Boquetillo en primer plano

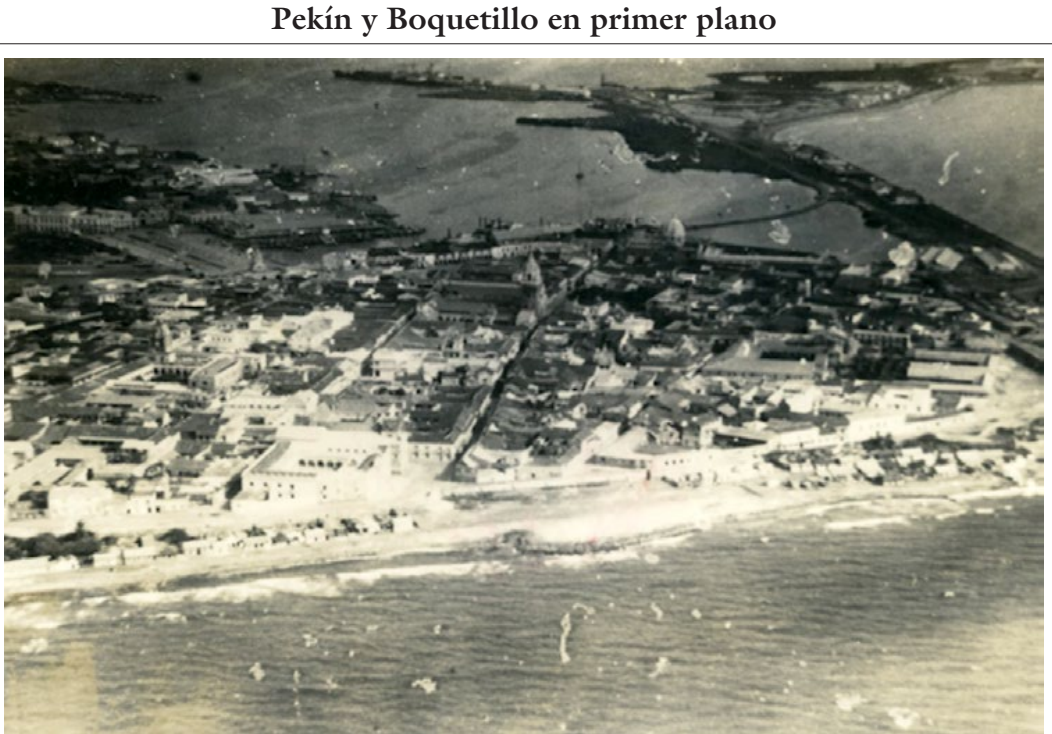




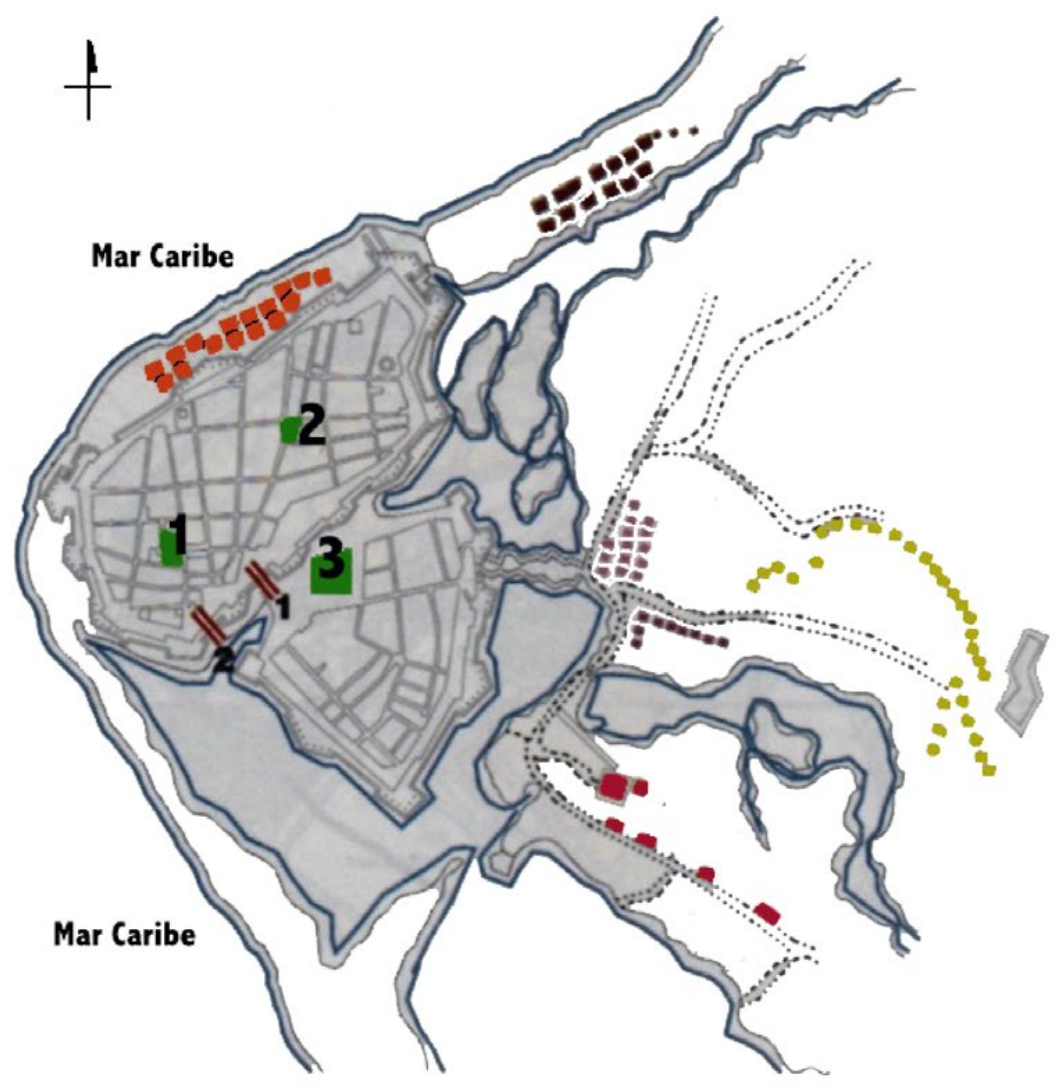

\section{Estructura Urbana Siglo XIX, \\ Plazas, Invasiones, Caserios}

$\square$ Plazas

1. Parque de Bolivar

2. Parque Fernández Madrid

3. Plaza de la Independencia

Invasiones

Boquetillo

Pekín

. Pueblo Nuevo

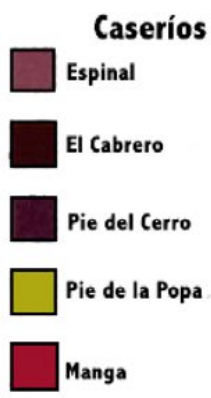

\section{Estructura Militar}

Puertas de acceso
1- Puerta de la boca del puente

2. Puerta de la Aduana o Piñeres (Puerta)

Fuente: Plano parcial de Manga, por

A. Buonpensiere y Terraohien, Cartagena, 1849.

Fuente: Modificado (Redondo, 2004, p. 159).

\section{La transición}

El segundo momento o de transición, observado en el equipamiento urbano que adquiere Cartagena, se ubica cronológicamente entre los años 1944 y 1947. En esta fase la ciudad - por iniciativa de las autoridades nacionales y locales - se abrirá hacía la actividad turística, dado, princi- palmente, su carácter histórico (Montoya, 1936). Dos obras marcarían el inicio de un nuevo hito económico para la urbe, la apertura del hotel Caribe en 1946 (Calvo et al., 1999) y la construcción de la pista del aeropuerto de Crespo en 1947 (Otero, 2012).

El posicionamiento como ciudad turística, además de implicar las construcciones territarias 36 179 
para el desarrollo de este sector, impulsó a las autoridades locales y nacionales a adoptar decisiones que facilitaran la construcción de una serie de obras públicas en la ciudad. Es así como el Concejo Municipal, en 1943, solicita al gobierno nacional la aprobación del plan de obras públicas, $\mathrm{CO}^{-}$ nocido como el plan de los doce millones (\$12.000.000). El Congreso de la República, mediante la Ley 8 de 1944, aprobó el plan y determinó lo siguiente:

[...] Artículo $3^{\circ}$ : Para todos los efectos legales, declárese de utilidad pública, las siguientes obras:

Arreglo definitivo del Canal del Dique (Ley 30 de 1915,71 de 1919 y 261 de 1938)

Carretera Cartagena - Montería (Ley 139 de 1837)

Alcantarillado de Cartagena (Ley 10 de 1941)

Defensa de Cartagena, desde el Hotel Caribe hasta la Boquilla, en la parte que no corresponde a entidad particular (Ley 117 de 1936)

Avenida Santander (Ley 117 de 1936)

Levantamiento de los rieles sobrantes (Ley 62 de 1936)

Limpia, canalización, angostamiento y urbanización de las orillas de los caños de Cartagena (Ley 62 de 1937)

Estadium (Ley 72 de 1928)

Plan regulador de la ciudad futura.

Letrinas faltantes de Cartagena y sus corregimientos.

territarias 36 180
Rectificación y pavimentación de avenidas principales.

Casa de maternidad, para la infancia y demás obras para asistencia social.

Matadero moderno.

Cementerio nuevo.

Construcción y reparación de parques en Cartagena y sus corregimientos.

Crematorios; y

Aguadas en los corregimientos. (Anales del Concejo de Cartagena, 1948, pp.43-46)

Este plan que sería financiado por empréstitos al sector privado se ejecutó parcialmente. La ola de impuestos anunciados y las rivalidades políticas (El Fígaro, 1945 ) crearon un clima de tensión en la ciudad que dilató la realización de los trabajos proyectados y muchas de las acciones, prioritarias para la ciudad, serían postergadas. Obras como el alcantarillado no se ejecutarían sino hasta 1960 (Calvo et al., 1999) y solo en el sector amurallado. En el fondo de esta problemática subyace una realidad que aún para los años 40 no se había podido superar: la ciudad seguía siendo profundamente pobre. A propósito de esto, un columnista de El Fígaro comentaba, con una visión crítica, sobre lo que denominó "proyectomanía” lo siguiente: "La verdad es que Cartagena es una ciudad de una pobreza franciscana. Todos los proyectos y todas las mejores intenciones se estrellan aquí contra un obstáculo insuperable: el obstáculo de la falta de plata" (El Fígaro, 1945, p.2).

La precariedad de las rentas en el entonces municipio de Cartagena era tan 
extrema que el presupuesto para las obras públicas solo alcanzaba para rellenar baches de las calles y para asegurar los edificios oficiales que, literalmente, se estaban cayendo. Proyectos como la construcción de la concha acústica, la ciudad moderna, el Palacio Departamental, el Parque del Playón y la expropiación del Pie del Cerro, entre otros, jamás se realizaron o, en el mejor de los casos, debieron esperar tiempos más afortunados.

La renovación urbana pretendida en el plan de los doce millones, de nuevo se quedó en el tintero, pues las obras de adecuación y mantenimiento requeridas para proyectar a Cartagena como destino turístico fueron deficitarias. Peor aún era el paisaje que mostraban los barrios populares, construidos al vaivén de las necesidades habitacionales de sus pobladores, ante la ausencia de un plan de urbanismo coherente y práctico. Como corolario la ciudad presentará una cara fea y desagradable, para propios y extraños, motivo de frecuentes quejas por parte de la prensa local (El Fígaro, 1945).

No obstante el cuadro arisco y vetusto en el que se enmarca la ciudad, una edificación atrae el mayor interés de las autoridades y la opinión pública local. Se trata de la edificación del estadio de béisbol. Este escenario deportivo, cuya construcción inicial se proyectó en los terrenos de Chambacú, fue construido con dineros provenientes del impuesto adicional a los espectáculos públicos, celosamente amparados por las autoridades locales.
Como ninguna otra obra de la época, la construcción el Estadio 11 de Noviembre generó el mayor de los consensos en la ciudad (Anales del Concejo, 1947). Tras ocho meses de trabajo fue inaugurado a finales de 1947, en la proyectada villa olímpica, sirviendo de escenario a la IX Serie Mundial de Béisbol aficionado que, por primera vez, ganaría un seleccionado colombiano (Calvo et al., 1999).

\section{La diversificación}

La evidente frustración que se derivó de la experiencia urbanística agenciada en el país (Espinosa, 2006; Torres, 2011) que, para el caso de Cartagena, se endosaba tanto al Plan Pearson como al plan de los doce millones, condujo al gobierno nacional a emitir la Ley 88 de 1947 o Ley sobre el Fomento del Desarrollo Urbano del Municipio. Dicha Ley constituiría la política urbana del Estado colombiano y, por consiguiente, fue de obligatorio cumplimiento para todo el territorio nacional. Es precisamente a partir de la promulgación de esta normatividad que la ciudad de Cartagena ingresa a su tercera fase de equipamiento urbano, como lo determina el artículo séptimo de la norma:

Los municipios que tengan un presupuesto no inferior a doscientos mil pesos (\$200.000) están en la obligación de levantar el Plano Regulador que indique la manera como debe continuarse la urbanización futura de la ciudad. Este plano no solo comprenderá las enmiendas y mejoras territarias 36

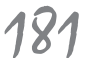


que deban hacerse a la parte ya construida, atendiendo al posible desarrollo, si no los nuevos barrios que hayan de levantarse, así como los sitios de recreo y deporte, templos, plazas y áreas verdes, escuelas y demás edificios necesarios a la población. (Diario oficial, 1948)

Este artículo definiría la corriente urbanística que los municipios debían seguir a fin de superar los viejos modelos que frenaban el progreso de las ciudades y el país. El objetivo, por lo tanto, era modernizar las urbes colombianas, hacerlas funcionales y adecuarlas a las exigencias de una población cada vez más citadina e inmersa en las lógicas del mercado. El patrón a seguir, entonces, fue el funcionalismo (Fuente, 1999): corriente arquitectónica defendida, entre otros, por el arquitecto Le Corbusier quien personalmente estuvo encargado del Plan Piloto de Bogotá de 1950 (Espinosa, 2006). Los argumentos centrales del funcionalismo aparecen en la Carta de Atenas, documento en el que se expresa que:

Las claves del urbanismo se encuentran en las cuatro funciones: habitar, trabajar, recrearse y circular.

El urbanismo tiene cuatro objetivos que son:

Primero. Asegurar a los hombres alojamiento sano, es decir, lugares en que el espacio, el aire puro y el sol, estás tres condiciones de

\section{territarias 36} naturaleza estén ampliamente aseguradas.
Segundo. Organizar los lugares de trabajo de modo que éste, en vez de ser una penosa sujeción, recupere su carácter de actividad humana natural.

Tercero. Prever las instalaciones necesarias para una buena utilización de las horas libres, haciéndolas beneficiosas y fecundas.

Cuarto. Establecer el vínculo entre diversas organizaciones por medio de una red circulatoria que asegure los intercambios sin dejar de respetar las prerrogativas de cada una de ellas. Estos cuatro objetivos son las cuatro claves del urbanismo, (Fuente, 1999, p. 245)

Es así que con el Plano Regulador de 1948, de explícita orientación funcionalista, se pretende diversificar la posibilidad de desarrollo y modernización de la ciudad de Cartagena. Propuesta que, además, será aprovechada como una oportunidad para ampliar el espectro de oportunidades económicas. Para ello se hace acopio de su potencial de centro de negocios, comercio, turismo e industria, sin dejar de lado su vocación de puerto. No obstante, con el nuevo proyecto, los traumatismos generados por las limitaciones del plan Pearson en materia económica, social y urbana no fueron superados en su totalidad.

El Plano Regulador respondió a la necesidad de adaptar la ciudad a un viraje de estrategia económica, además de servir como instrumento para solucionar los problemas de infraestructura y urbanismo del presente y del futuro. En este sentido, durante la vigencia del Plano Regulador, 
aparecen en la ciudad obras de equipamiento urbano que facilitarán el despegue económico y la modernización de algunos sectores de la urbe. Se construye la Avenida Pedro de Heredia, se inaugura la refinería de Intercol, aparece el primer tramo del alcantarillado en el sector amurallado, se inaugura el hotel Americano (Báez et al., 1999) y se levanta el complejo comercial de la Matuna.

Ciertamente estas grandes obras que adquirió la ciudad facilitaron enfrentar la expansión demográfica y urbana experimentada a mitad de siglo XX. (Báez et al., 1999) También es cierto que Cartagena adquirió la infraestructura para diversificar sus actividades económicas que le permitieron salir de la prolongada recesión a la que estuvo sometida durante la primera mitad del siglo. Pero además, es cierto que la imponencia del naciente sector industrial de Mamonal y la opulencia de los hoteles cinco estrellas de Bocagrande contrastarían con la miseria e inopia en que vivían los cartageneros de los barrios pobres.

Documentos oficiales y registros de la prensa permiten apreciar la preocupación de las autoridades locales por las condiciones deplorables en que se encontraban los barrios populares. Es más, estas autoridades, obligadas de cierta manera por las disposiciones del gobierno central y la opinión recurrente de la prensa local, plantearon algunas medidas que contribuyeran a disminuir las penurias de los "menos afortunados". Por ejemplo, en 1948, el Alcalde Mayor de Cartagena, mediante el Decreto 119 de mayo 11, designa a los miembros de las juntas de mejoras de los barrios Lo Amador y Canapote (Anales del Concejo, 1948); otro ejemplo ocurre en 1949, cuando el Concejo de Cartagena, mediante acuerdo, autoriza al personero municipal la adjudicación de terrenos de propiedad del municipio "a los pobres sin vivienda, para la vivienda popular y otras disposiciones" (Anales del Concejo, 1949, p.25).

Sin embargo, - - y este es uno de los grandes contrasentidos de la ciudaddurante la vigencia del plano regulador, cuando la ciudad alcanza su despegue económico, surgen y se consolidan extensos cinturones de miseria. Barrios pobres como Chambacú (Figura 6) y la zona sur oriental, sin el equipamiento urbano mínimo, serán la muestra de esa otra Cartagena que se construye en el fango. Las distancias espaciales en Cartagena se tornan cortas con la construcción de avenidas, como la avenida Pedro Romero, pero los distanciamientos económicos y sociales se vuelven absolutos.

\section{Conclusiones}

El espíritu modernizador del Plan Pearson y del plano Regulador contrastaría con la timidez de sus reales alcances, como lo expresaban los articulistas de la prensa local a lo largo de la primera mitad del siglo XX. Sus logros se circunscribieron a ciertas mejoras del puerto y a una limitada renovación urbana, especialmente en los sectores zonificados como ejes del desarrollo económico. Evento que se explica porque Cartagena, a pesar de su leve re- territarias 36

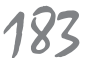




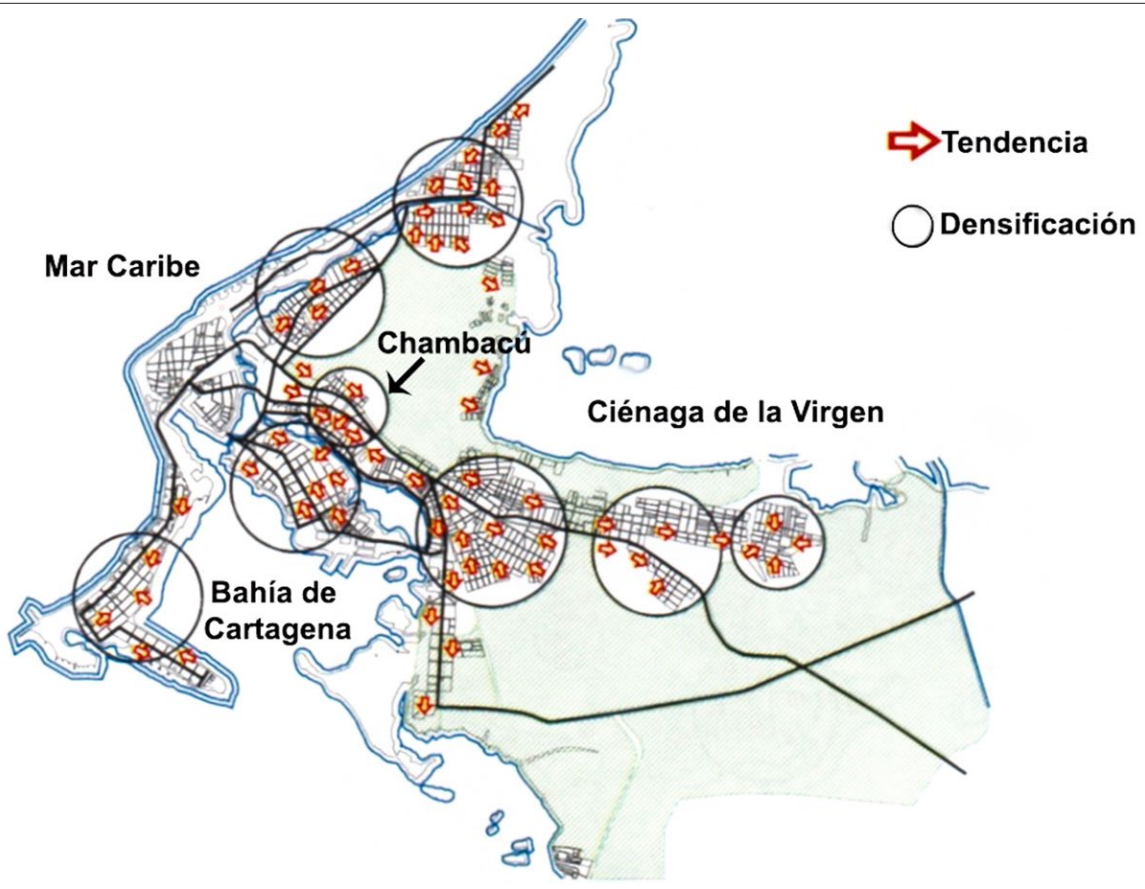

Fuente: Modificado (Redondo, 2004, p. 165).

cuperación económica, seguía siendo una ciudad pobre y marginal en el contexto de la economía regional y nacional. Los anhelos de progreso, modernidad, desarrollo económico y ascenso social que se concretaban en sanidad, higiene, servicios públicos extendidos, servicios médicos y hospitalarios, vías de transporte y comunicaciones, coherentes con los rasgos de la modernidad y la modernización, no fueron cumplidos.

Si bien fue visible la adquisición de cierto equipamiento urbano, las necesidades de los sectores pobres no fueron atendidas, más bien hubo negligencia y abandono. Es más, los barrios denominados como "pobres" fueron estigmatizados como espacios antihigiénicos e inmorales que había que sanear en aras de la modernización. La planeación y ejecución del desalojo de Pekín, Pueblo Nuevo, Boquetillo y Chambacú, el barrio popular de mayor importancia en la urbe del siglo XX, confirman lo que, temerariamente, podemos calificar como un "blanqueamiento" del territorio.

La pretendida modernidad, a imagen y semejanza de las urbes del viejo continente, se redujo a la imaginación de una élite que saciaba su intentada emulación 
en retóricos discursos de salón. Si acaso la ciudad experimentó la modernidad urbana, esta fue desde abajo. Dos serían los rasgos de ésta realidad: un acelerado crecimiento demográfico y una extensión territorial desprovista de ordenamiento. Los sectores populares de Cartagena surgirían, entonces, como una expresión de adaptación y resistencia de sus gentes, ante unas decisiones políticas que los invisibilizaban. Sin embargo, la presencia de barrios marginales testimonia la existencia de unos actores sociales que, con lógicas diferentes, aportaron a la configuración de la ciudad. En este sentido, como lo afirma Suárez, la historiografía urbana colombiana permite observar cómo se contraponen dos experiencias urbanísticas modernas: una desde abajo y otra desde arriba cuyo criterio será el que finalmente, y por lo menos como discurso, se impone, generando marcados rasgos de exclusión social, característicos en la historia de nuestras ciudades colombianas (2006).

El discurso de las autoridades locales, insinuado tanto en Pearson como el Plano Regulador, hallaría su reprobación en el recurrente examen de la prensa local. $\mathrm{Pu}$ blicaciones que día tras día daban cuenta de una realidad que diametralmente se alejaba de la estampa de una ciudad remozada y próspera. La diversidad y prodigalidad, de periódicos y artículos, dedicados al seguimiento de la evolución de Cartagena permiten concluir que la construcción de la ciudad es el resultado de relaciones de poder que se trenzaron en ella y de las múl- tiples representaciones de orden cultural que se confrontaron.

\section{Referencias}

Actividades de Acción Cívica (25 de enero de 1945), El Fígaro, p. 2.

Alcaldía de Cartagena, Programa de las $\mathrm{Na}$ ciones Unidas para el Medio Ambiente (PNUMA), Establecimiento Público Ambiental de Cartagena - EPA Cartagena \& Observatorio del Caribe Colombiano, (2009). Perspectivas del Medio Ambiente Urbano: GEO Cartagena. Cartagena: Programa de las Naciones Unidas para el Medio Ambiente.

Aguilera, M. (2006). El Canal del Dique y su subregión: una economía basada en la riqueza hidráulica. Documentos de trabajo sobre economía regional, $\mathrm{N}^{\circ} 72$. Banco de la República, Centro de Estudios Económicos Regionales (CEERN) Cartagena, Colombia.

Báez, J. \& Calvo, H. (1999). La economía de Cartagena en la segunda mitad del siglo XX: Diversificación y rezago. En Serie de estudios sobre la Costa Caribe. (pp. 33-114) Cartagena de Indias: Centro de investigaciones económicas del Caribe colombiano del Banco de la República

Bonilla, G. (2012). Las mujeres en la prensa en Cartagena de Indias (1900-1930). Cartagena: Ed. Universidad de Cartagena.

Cartagena ahora (15 de enero de 1945), El Figaro, p. 2. territarias 36

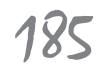


Calvo, H. \& Meisel, A. (1999). Cartagena de Indias en el Siglo XX (Comp). Bogotá: Universidad Jorge Tadeo Lozano \& Banco de la República.

Casas, A. (jul - dic, 1996). Agua y aseo en la formación de la salud pública en Cartagena 1885-1930. Revista Historia y Cultura de la Facultad de Ciencias Humanas (4), 77-100.

Cartagena a "oscuras" ( 4 de junio de 1948), El Universal, p. 6.

Chambacú grande y las basuras (2 de mayo de 1914), El Porvenir, p. 3.

Colombia, Concejo de Cartagena. Acta $\mathrm{N}^{\mathrm{o}} 25, \mathrm{~A}$ los pobres sin vivienda, para la vivienda popular y otras disposiciones. Por la cual se da una autorización al personero (30 de mayo de 1949) .

Colombia, Concejo de Cartagena. Acta $\mathrm{N}^{\circ} 3$, de la sesión ordinaria del $\mathrm{H}$. concejo Municipal (18 de noviembre de 1947).

Colombia, Alcaldía de Cartagena. Decreto 119 , por el cual se designa a los miembros de las juntas de mejoras de los barrios Lo Amador y Canapote (11 de mayo de 1948).

Colombia, Congreso de la República. Ley 8 de 1944, Plan de los 12 millones para la Ciudad de Cartagena. En Anales del Consejo de Cartagena (29 de febrero de 1948).

Colombia, Congreso de la República. Ley 33 de 1913, por la cual se organiza la Higiene Nacional pública y privada (3 de enero de 1914).

territarias 36

Colombia, Congreso de la República. Ley 88 , Sobre el fomento del desarrollo urbano del municipio y se dictan otras disposiciones ( 8 de enero de 1948)

Corredor, C. (2001). La modernización inconclusa. En G. Misas (Ed.), Desarrollo económico y social en Colombia. Siglo $X X$ (pp. 15-37). Bogotá: Universidad Nacional de Colombia.

El alumbrado eléctrico en los barrios costaneros (23 de diciembre de 1929), La Patria, p. 3.

Dilación en la adjudicación de las obras de ensanchamiento de la planta eléctrica (26 de mayo de 1948), El Universal, p.2.

Encuesta: Los males de la Ciudad ( 4 de junio de 1948), El Universal, p.10.

Espinosa, L. (2006). El Plan Piloto de Cali 1950. En Revista Bitácora, 1(10), 222-224. Recuperado de http://www. redalyc.org/articulo.oa?id=74801019 Estrella, E. (1995). La presencia de la Organización Panamericana de la Salud en la salud pública continental en el siglo XX y la importancia histórica del Código Sanitario Panamericano. Cuad, Historia de la Salud Pública. La Habana, pp.36-48.

Fainboim, I. \& Rodríguez, J. (2000) El desarrollo de la infraestructura en Colombia en la década de los noventa. Bogotá: CEPAL.

Fuente, M. (1999). Diccionario de historia urbana y urbanismo. El lenguaje de la ciudad en el tiempo. Madrid: Boletín oficial del Estado.

Grave necesidad pública (noviembre, 1948), Anales del Concejo Municipal, p. 40. 
Hernández, M. (2008). Exclusión social y desigualdad. Murcia: Ed. Universidad de Murcia.

Ingobernabilidad y desorden (27 de mayo de 1903), El Porvenir, p. 4.

La Avenida Santander (20 de enero de 1939), Gaceta del Departamento de Bolivar, pp. 1-2.

La calle de las damas (27 de noviembre de 1915), La Unión Comercial, p. 3.

La situación de la planta (26 de agosto de 1915), La Unión Comercial, p. 2.

Las basuras en Cartagena (30 de noviembre de 1927), Gaceta Municipal, pp. 1-8.

Lemaitre, E. (1983). Historia general de Cartagena. Bogotá: Banco de la República.

León, E. (ene-jun, 2006). La historia de la empresa distrital de servicios de Bogotá: construcción social de un declive organizacional. Revista Facultad Ciencias Económicas: Investigación y Reflexión, 14(1), 135-172.

Libro de Actas (18 de noviembre de 1947), Anales del Concejo Municipal, pp. 13-14.

Lo que la ciudad debe sabe ( 23 de mayo de 1948), El Universal, p. 2.

Los barrios pobres de Cartagena (12 de enero de 1945), El Fígaro, p. 7.

Los Fantasmas del concejo (12 de enero de 1945), El Figaro, p. 6. Meisel, A. (1999). Cartagena 1900-1950 A remolque de la economía nacional. [Presentación en pdf]. Recuperado de http:// www.banrep.gov.co/sites/default/files/publicaciones/archivos/cartagenahistoria.pdf
Montoya, J. (1936). Para el turista extranjero (for turists) en Cartagena en 1936. Cartagena: Empresa Editorial El Mercurio.

Nuestros problemas locales ( 5 de junio de 1948), El Universal, p. 2

Otero, A. (2012). La infraestructura aeroportuaria del Caribe colombiano. Documentos de trabajo sobre economía regional $\mathrm{N}^{\circ}$ 163, (p.11) Banco de la República, Centro de Estudios Económicos Regionales (CEER). Cartagena, Colombia.

Otro Proyecto descabellado (19 de enero de 1945), El Figaro, p. 3.

Por Cartagena. Saneamiento de la ciudad (14 de enero de 1914), El Porvenir, p. 3.

Por los monumentos históricos ( 5 de marzo de 1927), Diario de la Costa, p. 2.

Proyectomania (19 de enero de 1945), El Figaro, p. 2.

Redondo, M. (2004). Cartagena de Indias. Cinco siglos de evolución urbanistica. Bogotá: Fundación Universidad de Bogotá Jorge Tadeo Lozano.

Rivales en el progreso (12 de enero de 1945), El Figaro, pp. 3-6.

Serge, R. (1999). Historia de la arquitectura y el urbanismo. Países desarrollados. Siglos XIX y XX. En M. J. Fuente (Comp.), Diccionario de historia urbana y urbanismo. El lenguaje de la ciudad en el tiempo, (p. 252). Madrid: Boletín oficial del Estado.

Sobre ampliación de la calle del Camposanto (25 de enero de 1945), El Fígaro, p. 3. territarias 36

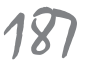

MODERNIZACIÓN URBANA Y EXCLUSIÓN SOCIAL EN CARTAGENA DE INDIAS, UNA MIRADA DESDE LA PRENSA LOCAL 
Sobre aseo, conservación y embellecimiento de las murallas ( 25 de enero de 1945), El Fígaro, pp.2- 3.

Sobre escuela y fondo del estadio (16 de enero de 1945), El Fígaro, p. 2.

Suárez, A. (2006). La ciudad de los elegidos. Crecimiento urbano, jerarquización socialy poder político. Bogotá (1910-1950). Bogotá: Editora Guadalupe Ltda.

Tabarquino, R. (2011). Los servicios públicos domiciliarios en Colombia: una mirada desde la ciencia de la política pública y la regulación acerca de los Servicios públicos Domiciliarios en Colombia. Santiago de Cali: Autor. Recuperado de http://www.eumed.net/librosgratis/2011c/997/indice.htm

Terrenos para el polígono de tiro en el Boquetillo. Razonado memorial de los vecinos de esta barriada al alcalde (21 de octubre de 1929), La Patria, p. 2.

Telegrama al Congreso de la República (23 de septiembre de 1915), La Unión Comercial, p.l.

Trabas para la provisión de cloro $(2$ de junio de 1948), El Universal, p.2

Torres, C. (2004). Reflexiones sobre el contexto del urbanismo en Colombia. En
Maestría en Urbanismo (Ed.), Urbanismo ¿Cambios o permanencias? (pp. 110-121). Bogotá: Universidad Nacional de Colombia.

Una laudable iniciativa del comité del Cabrero (26 de enero de 1945), El Fígaro, p. 2.

Una obra de urgente realización ( 24 de enero de 1945), El Fígaro, p. 2.

Una petición al señor Administrador de la CIA de Servicios Públicos ( 12 de enero de 1945), El Fígaro, p. 2.

Varela, E. (jul-dic, 2007). Las privatizaciones en Cartagena y Barranquilla. Un paradigma mercantilista en la gestión de los servicios públicos domiciliarios en Colombia. Revista Pensamiento é gestión, (23), 209-255.

Viloria, J. (2011). Historia del Banco de la República en Cartagena 1923-1929. [Presentación de Power Point] Recuperado de www.banrep.gov.co/documentos/publicaciones.

Zabaleta, R. (2012). Investigación histórica antigua Iglesia de San Francisco, boy abandonado Teatro Colón. Cartagena: Editorial Bonaventuriana. 